\title{
Determinants of household dietary diversity in Yayu Biosphere Reserve, Southwest Ethiopia
}

\author{
Geremew Motuma Jebessa ${ }^{1, *}$, Akalu Dafisa Sima ${ }^{1}$ and Beneberu Assefa \\ Wondimagegnhu ${ }^{2}$
}

${ }^{1}$ Department of Rural Development and Agricultural Extension, College of Agriculture and Veterinary Medicine, Jimma University, Ethiopia ${ }^{2}$ Department of Rural Development and Agricultural Extension, College of Agriculture and Environmental Sciences, Bahir Dar University, Ethiopia

\begin{abstract}
Lack of dietary diversity is a severe problem among the poor in the developing world, including Ethiopia. Empirical evidence for factors contributing to low dietary diversity hardly exists. The objective of this study was to analyze determinants of Household Dietary Diversity and consumption behavior in Yayu biosphere reserve, South-West Ethiopia. A cross sectional survey was conducted on 183 randomly selected households. Primary data were collected from sample households through interviews, focus group discussions and key informant interviews. Secondary data were collected by reviewing different documents. Descriptive statistics and econometric models were used for analyzing quantitative data. The ordered logit model was employed to determine the influence of explanatory variables on the dependent variable. The average household dietary diversity score was $5.5 \pm 1.7 \mathrm{SD}$. About $17.5 \%$ of the sampled households belonged to low, $61.2 \%$ to medium and $21.3 \%$ to high dietary diversity. The age of the household head, education, income, access to irrigation, home gardening and dietary diversity awareness affected household dietary diversity positively and significantly and distance from market negatively. In conclusion, policy and development interventions should target education and awareness creation tools to provide households up to date nutritional knowledge and agricultural technologies to increase production and income, and thereby enhance household dietary diversity.
\end{abstract}

Keywords: Household Dietary Diversity Ordered Logit, Yayu Biosphere Reserve, Ethiopia.

DOI: https://dx.doi.org/10.4314/ejst.v12i1.3

${ }^{*}$ Corresponding author: geremewmotuma@gmail.com, Tel:

$+251913870631$ 


\section{INTRODUCTION}

Poor quality diets are the norm in resource limited environments across the globe. Risks for a range of micronutrient deficiencies are high when grain or tuber-based staple foods dominate (Daniels, 2009). The current global nutrition situation indicates that malnutrition, in all its forms (under-nutrition, micronutrient deficiencies, overweight and obesity) is widespread (Grace, 2016). The report from FAO (2013) indicates that the diets of developing countries have improved except Africa and Southern Asia. Africa and Southern Asia did not fully benefit from improvements and their diets remain unbalanced and heavily dependent on stable crops. Dietary diversity refers to increasing the consumption of a variety of foods across and within the food groups and is considered to be one that is constituted of foods from all food groups so as to ensure that the population has adequate amounts of key nutrients to attain and maintain acceptable levels of growth and development (Ruel et al., 2013). While adequate food is necessary for optimal development and performance, lack of optimum number of essential micronutrients in the daily food intake of individuals is yet another form of food insecurity, a challenge in most developing countries (FAO, 2012). Because no single food can contain all required nutrients, dietary diversity has been conjectured to have greater practical potential of meeting nutrient requirements (Labadarios et al., 2011). Ensuring dietary diversity is a challenge for rural communities in developing countries like Ethiopia (Kennedy et al., 2007; Kibrom Sibhatu et al., 2015), a major cause of micronutrient malnutrition in sub-Saharan Africa (FAO, 2013; Thompson and Meerman, 2014) and starch dominated staples with inadequate animal products, fresh fruits and vegetables (Getnet Mekuria et al., 201). Less than $4 \%$ of the children in rural Ethiopia were fed with four or fewer food groups out of seven food groups (EDHS, 2011) and it was found that the average child eats 1.46 food groups per day (IFPRI, 2015) and the mean of household dietary diversity score was 4.7 and $40 \%$ of households are with low dietary diversity (Smith et al., 2006). Animal source food (ASF), fruits and vegetables are not a common diet items, whereas cereals contribute about $75 \%$ of the Ethiopian diet (Nguyen et al., 2013; Abdulhalik Workicho et al., 2016). A complex combination of underlying social, economic, physical, and environmental factors 
affects dietary diversity and food consumption behavior of individuals and communities. Key determinants of household dietary diversity vary by context, i.e., cultural beliefs and taboos, social and income status, intra-household food distribution, market dynamics, knowledge, and gender (Taruvinga et al., 2013) and extent of technology related with food production, processing, preparation and storage (Keding et al., 2013).

Ethiopia has improved dietary energy supply while dietary diversity remained low. The estimation from the Central Statistical Agency (CSA) shows that the average energy consumption increased from 2,200 kcals/capita/day in 2000 to over $2400 \mathrm{kcals}$ by 2011 (FMOH, 2016). However, the dietary patterns reported from the survey showed little change from 2005 to 2010 , demonstrating pervasive low dietary diversity. Some $60 \%$ of households had low and $40 \%$ medium diet diversity scores, indicating poor dietary preferences and consumption patterns in Ethiopia (Alemayehu Seyoum et al., 2012; Degye Goshu et al., 2013). The feeding practices of Ethiopian families remain sub-optimal. Only $4.3 \%$ of children consumed the recommended four food groups per day (FDRE, 2013).

In Ethiopia, dietary energy supply has improved while diversity remained low (insufficient protein, vitamin and minerals) (IFPRI, 2018). Many studies focused on determinants of household dietary energy consumption (or dietary quantity) and on individual dietary diversity at the expense of household dietary quality and diversity in Ethiopia. Need, therefore, arises to focus on household level of determinants of dietary diversity and dietary quality given the fact that a diverse diet (especially micronutrients) is normally rare in rural communities of developing countries. The Sustainable Development Goal that is ending all forms of malnutrition cannot be achieved without optimum consumption of dietary diversity in countries like Ethiopia. Identifying the determinants of dietary diversity is vital to draw policy options, devise appropriate interventions, and ultimately help enhance investments in food and nutrition security. Almost no study has been conducted on identifying factors that affect household dietary diversity in Yayu Biosphere area. Therefore, the study was aimed to assess the determinants of household dietary diversity and consumption behavior in that area. Findings help stakeholders, policy makers and program planners working on livelihoods, agriculture, 
health sector, food and nutrition. They also provide baseline data and serve as reference for to future researchers.

\section{MATERIALS AND METHODS}

\section{Description of the study area}

The research was conducted in the Yayu Biosphere Reserve specifically in Achibo, Witate and Gechi kebeles of Yayu woreda which is situated in Ilu Ababora Zone of Oromia National Regional State and it is located about $582 \mathrm{Km}$ west of Addis Ababa. Its agroecology is lowland and highland. The mean annual temperature is about $20^{\circ} \mathrm{C}$ and the mean annual rainfall is $2100 \mathrm{~mm}$ per year. The Woreda has a total population of 57,938 (27,969 males and 29,969 females). About 11794 (9974 male and 1820 female) are households. Of the total population $20 \%$ are living in urban areas while the rest $80 \%$ are living in rural areas.

\section{Sample size and sampling procedure}

Sample selection was done employing three-stage sampling method. At the first stage, the study area was purposely selected. In the second stage, three kebeles (Achibo, Witate and Gechi) were selected out of a total 18 kebeles found within the biosphere area using simple random sampling method. At the end, 183 respondent households were selected from the three kebeles by systematic random sampling method. Table 1 summarizes the sample proportions in each kebele.

Table 1. Distribution of sampled households in the study area

\begin{tabular}{lcccccc}
\hline $\begin{array}{l}\text { Selected } \\
\text { PAs }\end{array}$ & \multicolumn{2}{c}{ Total household heads } & \multicolumn{3}{c}{ Sampled household heads } \\
& Male & Female & Total & Male & Female & Total \\
\hline Gechi & 666 & 129 & 795 & 31 & 19 & 49 \\
Witate & 831 & 191 & 1022 & 43 & 22 & 63 \\
Achibo & 921 & 190 & 1111 & 53 & 15 & 68 \\
\hline
\end{tabular}

*Peasant association 


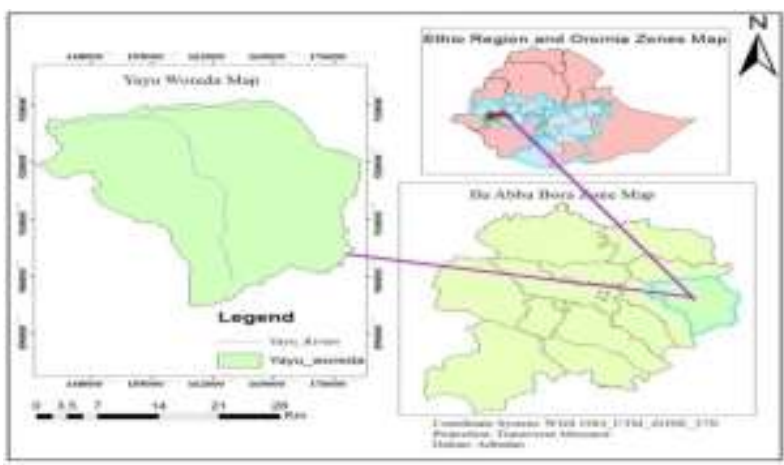

Figure 1. Geographic location of Yayu woreda in Ethiopia

\section{Data types, sources and collection methods}

A cross-sectional survey was conducted in rural households of the study area. In this study, both qualitative and quantitative data type were collected from both primary and secondary sources of data. Primary data were collected from sampled households using semistructured questionnaire, interview guide for Focused Group Discussion (FGD) and key informant checklist. Secondary data were gathered from woreda offices and from published documents.

Using the FAO guidelines for measuring household dietary diversity (FAO, 2008), the dietary diversity was assessed based on the number of food groups consumed over the immediate past 24 hour. The person who is responsible for preparing food in the previous day was interviewed to obtain information on foods consumed. The recall period of 24 hours has been chosen by FAO, as it is less subjective to recall error, less cumbersome for the respondent and also conforms to the recall time period used in many other dietary diversity studies (Steyn et al., 2006, Kennedy et al, 2007).

\section{Definition of variables and working hypotheses}

The dietary diversity tool has been proposed and used by FAO to measure and assess food groups consumed during a defined reference period and universally (Table 2). 
Table 2. Definition of the variables and measurements

\begin{tabular}{|c|c|c|c|c|}
\hline Acronym & $\begin{array}{l}\text { Independent } \\
\text { variables }\end{array}$ & Type & Unit & $\begin{array}{l}\text { Expected } \\
\text { sign }\end{array}$ \\
\hline SEXHH & $\begin{array}{l}\text { Sex (household } \\
\text { head) }\end{array}$ & Dummy & $\begin{array}{l}1 \text { male, } 0 \\
\text { female }\end{array}$ & $+\mathrm{ve}$ \\
\hline AGEHH & $\begin{array}{l}\text { Age (household } \\
\text { head) }\end{array}$ & Continuous & Years & -ve \\
\hline EDULEHH & Education level & Continuous & $\begin{array}{l}\text { Schooling } \\
\text { (years) }\end{array}$ & $+\mathrm{ve}$ \\
\hline HHSIZ & $\begin{array}{l}\text { Household size } \\
\text { (number) }\end{array}$ & Continuous & Number & -ve \\
\hline LANDSIZ & $\begin{array}{l}\text { Land holding } \\
\text { size }\end{array}$ & Continuous & Hectare & $+\mathrm{ve}$ \\
\hline LIVSOWN & $\begin{array}{l}\text { Livestock } \\
\text { owned }\end{array}$ & Continuous & $\begin{array}{l}\text { Tropical } \\
\text { livestock } \\
\text { unit }\end{array}$ & $+\mathrm{ve}$ \\
\hline ACIRR & $\begin{array}{l}\text { Access to } \\
\text { irrigation }\end{array}$ & Dummy & $\begin{array}{l}1 \text { access, } 0 \\
\text { no access }\end{array}$ & $+\mathrm{ve}$ \\
\hline HOMGARD & $\begin{array}{l}\text { Home garden } \\
\text { practice }\end{array}$ & Dummy & $\begin{array}{l}1 \text { for yes, } 0 \\
\text { for none }\end{array}$ & $+\mathrm{ve}$ \\
\hline INCOME & $\begin{array}{l}\text { Income of } \\
\text { household }\end{array}$ & Continuous & Birr & $+\mathrm{ve}$ \\
\hline MARDIS & Market distance & Continuous & $\mathrm{km}$ & -ve \\
\hline EXTCONT & $\begin{array}{l}\text { Agric. extension } \\
\text { contacts }\end{array}$ & Continuous & $\begin{array}{l}\text { Contacts per } \\
\text { year }\end{array}$ & $+\mathrm{ve}$ \\
\hline AGINPUT & $\begin{array}{l}\text { Agricultural } \\
\text { inputs use }\end{array}$ & Dummy & $\begin{array}{l}1 \text { for use, } 0 \\
\text { for none }\end{array}$ & $+\mathrm{ve}$ \\
\hline HEWCONT & $\begin{array}{l}\text { Health extension } \\
\text { contact }\end{array}$ & Continuous & $\begin{array}{l}\text { Contacts per } \\
\text { year }\end{array}$ & $+\mathrm{ve}$ \\
\hline CREDUSE & Credit use & Dummy & $\begin{array}{l}1 \text { use, } 0 \text { for } \\
\text { none }\end{array}$ & $+\mathrm{ve}$ \\
\hline AWARDD & $\begin{array}{l}\text { Awareness } \\
\text { (dietary } \\
\text { diversity) }\end{array}$ & Dummy & $\begin{array}{l}1 \text { aware, } 0 \\
\text { for not }\end{array}$ & $+\mathrm{ve}$ \\
\hline NUTRKNO & $\begin{array}{l}\text { Nutritional } \\
\text { knowledge }\end{array}$ & Continuous & $\begin{array}{l}\text { Score from } \\
1-7\end{array}$ & $+\mathrm{ve}$ \\
\hline
\end{tabular}

Note: Household Dietary Diversity (HDD) Status (Low HDDS = 0; Medium HDDS $=1$ and High HDDS $=2$ ). recognized as a key component of healthy diets (FAO, 2008); Low HDD $=0$ (if the dietary diversity score of households is less than four), Medium HDD =1 (if four to six), High HDD = 2 (if more than six).

\section{Methods of data analysis}

Data were analyzed using descriptive statistics and econometric model. Frequency distribution, mean, percentage distribution and standard deviations were employed. Chi-square analysis was 
employed for comparing groups such as sex of household head, access to irrigation, home gardening, fertilizer use, credit use awareness on dietary diversity and one-way ANOVA for comparing groups like age, education level, household size, land-holding size, livestock, income, market distance, extension contact and nutrition knowledge of households. Ordinal logistic regression model was used to determine the relationship between the dependent variables and a set of explanatory variables.

\section{The econometric model}

Ordered logit model is specified as follows: According to Green (2008), the ordered logit model regression equation takes the form:

$\mathrm{Y}^{*}=\sum_{k=1}^{k} \beta_{k} X_{k}+\varepsilon$

Where $\mathrm{Y}^{*}=$ is unobserved and thus can be thought of as the underlying tendency of an observed phenomenon,

$X_{\mathrm{k}}=\mathrm{A}$ vector of explanatory variables, $\beta=$ Coefficients to be estimated, and $\varepsilon=A$ random error term (assumed to follow a standard normal distribution for logistic distribution). There is a random disturbance term, which, in this case, has a standard logistic distribution. This reflects the fact that relevant variables may be left out of the equation, or variables may not be perfectly measured. The Ordered Logit Model estimates part of the above:

$\mathrm{Y}^{*}=\sum_{k=1}^{k} \beta_{k} X_{k}$

The observed or defined categorical variable $\mathrm{Y}_{\mathrm{i}}$ is determined from the model as follows:

$\mathrm{y}=1$ if $\mathrm{y}^{*} \leq \mu 1$

$\mathrm{y}=2$ if $\mu 1<\mathrm{y}^{*} \leq \mu 2$

$\mathrm{y}=3$ if $\mu 2<\mathrm{y}^{*} \leq \mu 3$

$\mathrm{y}=\mathrm{j}$ if $\mu_{\mathrm{j}-1}<\mathrm{y}^{*}$

Where $y$ is observed in $\mathrm{j}$ number of ordered categories, $\mu$ 's are unknown threshold parameters separating the adjacent categories to be estimated with $\beta$ 's, so $\mu 1, \mu 2$, and $\mu 3$ is a set of thresholds of the household dietary diversity gap to be estimated. The general form for the probability that the observed y falls into category $\mathrm{j}$ and the $\mu$ 's and the $\beta \mathrm{s}$ are to be estimated with an ordinal logit model is: 


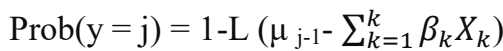

Where $\mathrm{L}(\cdot)$ represents cumulative logistic distribution.

\section{RESULTS AND DISCUSSION}

\section{Description of the sampled household characteristics}

A total of 183 households were involved in the analysis. The mean of age of the household head was 47.4 years and the average education level of households was 2.4 years of schooling. The mean of household size was 5.1. The average land holding of the households was 1.6 ha and livestock was 1.92 tropical livestock unit (TLU). Oneway ANOVA test revealed that age of household head, education level of the head, household size, land and livestock holding of the households had a significant mean difference among household dietary diversity categories (Table 3). The knowledge of households about nutrition did not vary; they had similar exposure. The average annual income of the households was 21,118 ETB. An increase in income enabled smallholders to diversify the diet and also to buy more non-food goods, and this tends to imply a greater dietary quality. The average distance taken to travel from home to the nearest market place was $4.4 \mathrm{kms}$. The average number of contacts with the agricultural extension agent was 9.7 and health extension workers 3.4 times per year (Table 3). The one-way ANOVA test showed significant difference between HDD categories in terms of income, distance to market, agricultural and health extension contacts. The survey result showed that out of the households sampled $79.2 \%$ of households were headed by males and $20.8 \%$ by females. Only $12 \%$ of heads of the households had access to irrigation and $79.2 \%$ of households participated in home garden production. About $13.7 \%$ of the households had access to credit and utilized the services. About $72 \%$ of the respondents had awareness of dietary diversity on the importance and health consequences of poor dietary diversity. The chi-square test indicated that there was significant difference among male and female headed households in terms of home garden practice, irrigation utilization and use of chemical fertilizers among household dietary diversity categories but not credit use (Table 4). 


\section{Dietary diversity status of households}

The study results showed that from 183 of households, $32(17.5 \%)$ participants consumed up to three food groups (low dietary diversity), $112(61.2 \%)$ consumed four to six food groups (medium dietary diversity), and 39 (21.3\%) participants consumed seven or more food groups (high dietary diversity) in their diet during the preceding 24 hours. The household dietary diversity scores ranged from 2 to 10 food groups with the mean of $5.5 \pm 1.7 \mathrm{SD}$. The mean dietary diversity scores of low household dietary diversity category was 2.94 , medium was 5.3 and high was 7.9 (Table 5). Similar findings were reported before in Ethiopia (Abdulhalik Workicho et al., 2016; Admassu Tesso et al., 2017).

\section{Food groups of households}

The finding of the study showed all participants (100\%) consumed cereals (Table 6). This implied that the households' diet was predominantly based on cereals. The findings of this study corroborate many previous studies (Vakili et al., 2013; Mkemwa, 2015; Mbwana et al., 2016) which reported the dominance of cereals. The consumption of root and tubers was reported by $46 \%$ of households as their meals in the past 24 hours. Likewise, from these households $62.2 \%$ were from high and $50 \%$ were from medium household dietary diversity category and only $14.7 \%$ were from low household dietary diversity category (Table 6). A similar result was also reported before (Tadesse et al., 2016). About $51.9 \%$ of the households reported consuming vegetables within the recent 24-hrs. These households were from high $(82.1 \%)$, medium (49\%) and low $(25 \%)$ household dietary diversity categories. Households did not consume Vitamin A rich dark green leafy vegetables. This observation is consistent with the study of Admassu Tesso et al., (2017). About $19 \%$ of the sampled households consumed fruits; from high household dietary diversity category $43.2 \%$ of them consumed it, while few percentages of the low and medium household dietary diversity category consumed fruits (Table 6). The findings indicate that intake of foods rich in animal sources was significantly low in terms of frequency for the entire sample. Only $27.3 \%$ of households consumed meat, $16.4 \%$ consumed dairy products and $22 \%$ consumed 
eggs. Households with high household dietary diversity consumed meat $(54.1 \%)$, dairy products $(24.3 \%)$ and eggs $(40.5 \%)$. Those with medium HDDS consumed meat, dairy product, and eggs, by $29.5 \%$, $18 \%$ and $21.4 \%$ of the sampled households, respectively. The proportion of animal source food consumption was higher among households with high HDDS than medium and low HDDS. This could be due to high income that enabled the people to purchase the expensive animal protein. This implied that households in low and medium category had low purchasing power and could not afford the expensive meat.

This finding is consistent with a previous study (Herrador et al., 2015; Bundala et al., 2017; Schwei et al., 2017). Fish was not consumed at all among households of the study area. Related findings were also reported before (Bekele Megersa et al., 2014; Getnet Mekuria et al., 2017). About $75 \%$ of households consumed legumes or nuts and seeds food group like lentils, beans and peas in the form of cooked (wot, kolo, and nephro). Low consumption of this food group limits the intake of plant protein, B vitamins and dietary fiber which are required for growth and development, especially in children and women of reproductive age (Mkemwa, 2015). From low, medium and high HDDS category $73.5 \%, 75.3 \%$ and $83.8 \%$ of households consumed this food group respectively (Table 6). The pattern followed previous reports (Mkemwa, 2015). In this study $86 \%$ of participants consumed oil, butter and fats food group. Households from low, medium and high HDDS category 61.8, 89.3 and 97.3\% consumed this food group respectively. The findings of this study were in line with those reported by Abdulhalik Workicho et al. (2016). Foods such as sugar, honey, cakes, biscuits and juice drinks were all in this group. Only $32.8 \%$ of respondents consumed different forms of sweets. Coffee, tea, local alcohols were most frequently consumed by all households; similar condition has been reported before (Tadesse et al., 2016). 
Table 3: Comparison of household dietary diversity categories (continuous explanatory variables)

\begin{tabular}{|c|c|c|c|c|c|c|c|c|c|}
\hline \multirow[t]{3}{*}{ Variables } & \multicolumn{8}{|c|}{ Household dietary diversity category } & \multirow{3}{*}{$\mathrm{F}$} \\
\hline & \multicolumn{2}{|c|}{ Low } & \multicolumn{2}{|c|}{ Medium } & \multicolumn{2}{|c|}{ High } & \multicolumn{2}{|c|}{ Total } & \\
\hline & Mean & SD & Mean & SD & Mean & SD & Mean & SD & \\
\hline Age & 40.8 & 8.5 & 49.6 & 8.0 & 48.6 & 7.2 & 47.4 & 8.7 & $13.24 * * *$ \\
\hline Education level & 0.6 & 1.6 & 2.0 & 2.7 & 5.2 & 2.8 & 2.4 & 3.0 & $32.23 * * *$ \\
\hline Household size & 4.1 & 1.5 & 5.3 & 1.6 & 5.4 & 1.6 & 5.1 & 1.6 & $8.59 * * *$ \\
\hline Land-holding size & 0.9 & 0.5 & 1.8 & 1.2 & 2.6 & 2.5 & 1.8 & 1.6 & $11.37 * * *$ \\
\hline Livestock & 0.8 & 1.1 & 2.0 & 1.8 & 2.7 & 3.0 & 1.9 & 2.1 & $15.07 * * *$ \\
\hline Income & 7081 & 4892 & 20064 & 21200 & 35661 & 69300 & 21118 & 36900 & $14.14 * * *$ \\
\hline Market distance & 4.7 & 1.4 & 4.5 & 1.4 & 3.9 & 1.2 & 4.4 & 1.4 & $9.01 * * *$ \\
\hline Extension contact & 3.5 & 6.8 & 10.6 & 11.8 & 12.5 & 13.4 & 9.7 & 11.8 & $7.22 * * *$ \\
\hline HEW contact & 2.5 & 3.7 & 3.2 & 3.4 & 4.4 & 3.8 & 3.4 & 3.6 & $5.44 * * *$ \\
\hline Nutrition knowledge & 2.4 & 2.6 & 2.5 & 3.2 & 4.5 & 3.6 & 2.7 & 3.3 & $1.87 \mathrm{NS}$ \\
\hline
\end{tabular}

***Significant at less than $1 \%$ probability level, NS $=$ non-significant

Source: Own survey, 2018 
Table 4. Comparison of household dietary diversity categories (dummy explanatory variables)

\begin{tabular}{|c|c|c|c|c|c|c|c|c|c|c|}
\hline \multirow{3}{*}{ Variables } & & \multicolumn{8}{|c|}{ Household dietary diversity category } & \multirow{3}{*}{$\chi^{2}$} \\
\hline & & \multicolumn{2}{|c|}{ Low } & \multicolumn{2}{|c|}{ Medium } & \multicolumn{2}{|c|}{ High } & \multicolumn{2}{|c|}{ Total } & \\
\hline & & $\mathbf{N}$ & $\%$ & $\mathbf{N}$ & $\%$ & $\mathbf{N}$ & $\%$ & $\mathbf{N}$ & $\%$ & \\
\hline \multirow[t]{2}{*}{ Sex of $\mathrm{HH}$} & Female & 10 & 31.2 & 24 & 21.4 & 4 & 10.3 & 38 & 20.8 & \\
\hline & Male & 22 & 68.8 & 88 & 78.6 & 35 & 89.7 & 145 & 79.2 & $14.382 * *$ \\
\hline \multirow{4}{*}{$\begin{array}{l}\text { Access to } \\
\text { irrigation } \\
\text { Home gardening }\end{array}$} & No & 32 & 100.0 & 98 & 87.5 & 31 & 79.5 & 116 & 88.0 & \\
\hline & Yes & 0 & 0.0 & 14 & 12.5 & 8 & 20.5 & 22 & 12.0 & $28.94 * * *$ \\
\hline & No & 12 & 37.5 & 24 & 21.4 & 2 & 5.0 & 38 & 20.8 & \\
\hline & Yes & 20 & 62.5 & 88 & 78.6 & 37 & 95.0 & 145 & 79.2 & $18.31 * * *$ \\
\hline \multirow[t]{2}{*}{ Fertilizer use } & No & 20 & 62.5 & 32 & 28.6 & 6 & 15.4 & 58 & 31.7 & \\
\hline & Use & 12 & 37.5 & 80 & 71.4 & 33 & 84.6 & 125 & 68.3 & $23.014 * * *$ \\
\hline \multirow[t]{2}{*}{ Credit use } & No & 25 & 79.4 & 98 & 87.5 & 35 & 89.2 & 158 & 86.3 & \\
\hline & Yes & 7 & 20.6 & 14 & 12.5 & 4 & 10.8 & 25 & 13.7 & $1.766^{\mathrm{NS}}$ \\
\hline \multirow{2}{*}{$\begin{array}{l}\text { Awareness on } \\
\text { DD }\end{array}$} & No & 18 & 56.0 & 31 & 27.7 & 9 & 22.7 & 51 & 28.0 & \\
\hline & Yes & 14 & 44.0 & 81 & 62.3 & 30 & 77.3 & 132 & 72.0 & $33.726 * * *$ \\
\hline
\end{tabular}

** Significant at 5\% probability level, *** at 1\%, and NS Non significant; Source: Own survey, 2018 
Table 5. Distribution of respondents by level of household dietary diversity

\begin{tabular}{llllllll}
\hline $\begin{array}{l}\text { HDDS } \\
\text { level }\end{array}$ & Frequency & \% & Range & Mean & SD & Max & Min \\
\hline Low & 32 & 17.5 & $1-3$ & 2.94 & 0.25 & 3 & 2 \\
Medium & 112 & 61.2 & $4-6$ & 5.3 & 0.8 & 6 & 4 \\
High & 39 & 21.3 & $7-12$ & 7.9 & 1 & 10 & 7 \\
Total & 183 & 100 & $1-12$ & 5.5 & 1.7 & 10 & 2 \\
\hline
\end{tabular}

Source: Own survey 2018; "max" stands for maximum, "min” for minimum

\section{Econometric analysis}

The variables assumed to have influence on household dietary diversity were tested in the model and out of 14 variables entered into the model eight of them were found to be significant while six of them were not found to be statistically significant.

Age of household head: Contrary to expectation, the age of household heads was found to be positively affecting dietary diversity of the household (Table 7). This is expected as age of a household increases, it is assumed that farmers could acquire more knowledge and experience, which can enhance their understanding on their diets. The model output indicates that holding other variable constant, for a one unit increase in age of household head's odds ratio in favor of high category with household dietary diversity increases by the factor of 1.353. Some previous reports appear to be claiming the opposite (Jones et al., 2014; Romeo et al., 2016; Ochieng et al., 2017).

Educational level of household head: As education increases the knowledge and skill of the people in a society, it has been hypothesized to have a positive relationship with household dietary diversity. As expected, education level of household head had a positive influence on the household dietary diversity. By holding the influence of other variables constant, a one unit increase in household head education level, the odds ratio in favor of high category with household dietary diversity increased by the factor of 1.538 . This implies education increases knowledge of nutritional diets and proved to be one of the most important determinants of dietary diversity consumption. Educated household heads could have better understanding on health benefits of consuming nutritious food so that 
they spent a higher amount of their food budget on diversified diet than uneducated ones. The findings agree with many previous findings on significance of education to household dietary diversity. Education of the household head plays a positive role for household dietary diversity (Taruvinga et al., 2013; Jones et al., 2014; Koppmair et al., 2016). The more households are educated, the more they are likely to attain a higher dietary diversity. Moreover, Davidson and Kropp (2017) described that educated household head is almost twice as likely to produce vitamin A rich fruits and vegetables for consumption. While Fuller et al. (2004) observed that educational achievements within the household, independent of the additional income it brings, increase consumption of NABs (Non-alcoholic beverage) such as fluids, milk and yogurt.

Livestock owned: Livestock ownership of households' significantly and positively influenced household dietary diversity. The model output indicates that keeping other variables constant, a unit increase in livestock ownership leads the odd ratio in favor of high category with household dietary diversity increase by a factor of 1.38 . This implies that households who own more livestock are more likely to diversify their diet than households owning a smaller number of livestock. The finding corroborates other studies that reported association between dietary diversity and livestock ownership (Rashid et al., 2011; Arega Bazezew, 2014; Bekele Megersa et al., 2014; Abdulhalik Workicho et al., 2016). Further, Taruvinga et al. (2013) indicated that rural households with livestock ownership are more likely to move from a medium dietary diversity status into a high dietary diversity status.

Access to irrigation: As expected, access to irrigation positively and significantly affected household dietary diversity. The result shows keeping the influence of other variables constant, household access to irrigation, the odd ratio in favor of high category with household dietary diversity increases by a factor of 5.824 . This implies that households who have access to irrigation are more likely to increase their dietary diversity than households without access to irrigation. 
Table 6. Food groups of households

\begin{tabular}{|c|c|c|c|c|c|c|c|c|}
\hline \multirow{3}{*}{ Food Groups } & \multicolumn{8}{|c|}{ Household dietary diversity category } \\
\hline & \multicolumn{2}{|c|}{ Low } & \multicolumn{2}{|c|}{ Medium } & \multicolumn{2}{|c|}{ High } & \multicolumn{2}{|c|}{ Total } \\
\hline & $\mathbf{N}$ & $\%$ & $\mathbf{N}$ & $\%$ & $\mathbf{N}$ & $\%$ & $\mathbf{N}$ & $\%$ \\
\hline Cereals & 32 & 100.0 & 112 & 100.0 & 39 & 100.0 & 183 & 100.0 \\
\hline Roots \& tubers & 4 & 12.5 & 56 & 50.0 & 24 & 62.5 & 84 & 46.0 \\
\hline Legumes \& pulses & 24 & 75.0 & 84 & 75.0 & 33 & 84.6 & 137 & 76.0 \\
\hline Vegetables & 8 & 25.0 & 55 & 49.1 & 32 & 82.1 & 96 & 51.9 \\
\hline Fruits & 2 & 6.0 & 15 & 13.2 & 17 & 43.2 & 34 & 18.7 \\
\hline Meats & 1 & 3.0 & 33 & 29.5 & 21 & 54.1 & 50 & 30.1 \\
\hline Eggs & 1 & 3.0 & 24 & 21.4 & 16 & 40.5 & 40 & 22.4 \\
\hline Fish & 0 & 0.0 & 0 & 0.0 & 0 & 0.0 & 0 & 0.0 \\
\hline Dairy products & 1 & 3.0 & 20 & 18.0 & 9 & 24.3 & 36 & 16.4 \\
\hline Oils \& fats & 19 & 61.8 & 100 & 89.3 & 38 & 97.3 & 157 & 86.0 \\
\hline Sweets & 3 & 8.8 & 31 & 27.7 & 27 & 70.3 & 60 & 32.8 \\
\hline Spices \& beverages & 20 & 63.0 & 100 & 89.2 & 38 & 97.3 & 157 & 86.0 \\
\hline
\end{tabular}

Source: Own survey, 2018 
The finding suggests that using irrigation enhance household dietary diversity due to the fact that it provides an opportunity for participants to grow a variety of cash and domestic horticultural crops which may directly improve their diet. Indirectly, cash crops from irrigation schemes can also improve household's food purchasing power. The finding is consistent with other reports (Headey and Ecker, 2012; Moyo and Machethe, 2016; Tizita Damtew, 2017).

Home gardening: Home gardening has affected household dietary diversity positively and significantly. Keeping the influence of other variables constant, household's access to home garden increases the odd ratio in favor of high category by a factor of 2.97. This implies that household with home gardening are more likely to diversify their diets than households without home gardening. Home gardening provides a means to access a variety of foods that may not be available in the market through cultivation of fruits, vegetables, and other crops. The finding of this study is congruent with previous studies (Zarihun Kebebew et al., 2011; Ajah et al. 2013; Galhena et al., 2013; Bundala, 2017) as they described cultivation of home gardening was an evident factor of having diverse diet for the household. Furthermore, Cabalda et al. (2011) suggested that home gardens normally provide a variety of diets like vegetables, fruits, and roots or tubers.

Income: Income is an important and significant indicator of the general economic well-being of a household and therefore assumes positive relationship for household dietary diversity. The positive relationship of this variable indicates that the higher income households are more likely to diversify their diet than poorer households. By controlling the influences of other variables constant, a one unit increases in income of household, the odds ratio in favor of high category with household dietary diversity increases by a factor of 1.202. The result is in line with the previous findings (Linderhof et al., 2016). Higher income increases dietary diversity at the household level and allows a household to the purchase of more food with higher nutritional quality. Higher agricultural revenue is associated with a higher probability that a household will consume diversified diet and have positive significant association (Arega Bazezew, 2014; Dillon et 
al., 2015). Income determines a household's level of consumption (Bamidele et al., 2010).

Awareness on dietary diversity: the ordered logit analysis indicates that dietary diversity awareness has a positive correlation with household dietary diversity and significant at $1 \%$ probability level as it was hypothesized. The model output result shows that holding other variable factors constant, the odd ratio in favor of high category with household dietary diversity increases by the factor of 4.036 for households who are aware about dietary diversity. This implies that awareness improves knowledge on the individual food items and helps to make general evaluations of the dietary diversity of that household. Nutrition aspects go along with knowledge and awareness to ensure proper selection of foods for good health. Awareness provides consumer information which would help to consume food wisely and relevant skills needed to prepare food well. The result is consistent with research findings of Powell et al. (2017) who reported that lack of nutrition information results into poor dietary eating that instigate to inadequate nutrients intake. Awareness encourages people to consume healthy meals and to carry out proper child feeding practices (Nathan, 2008; Nsele, 2014).

Distance to market: The ordered logit model result indicates that distance to market had significant and negative influence on household dietary diversity at $\alpha=0.05$. A one unit increase in market distance leads the odds ratio in favor of high category household dietary diversity to decrease by a factor of 0.643 . This agrees with Stifel and Minten (2017) who reported strong link between remoteness from markets and household dietary diversity. Kibrom Better market access through reduced distance could contribute to higher dietary diversity (Sibhatu et al., 2015; Hirvonen et al., 2017)

\section{CONCLUSION}

This study estimated status and determinants of household dietary diversity. The study demonstrated that the diet of all of the households was composed of cereal, legumes, oils and spices at the expense of 
animal source foods, fruits and vegetables. Foods from animal sources (meat, eggs and milk and milk products) were a rare component in the household's diets, particularly in households with low HDDS. The dietary diversity of the study area is indeed associated with different factors. The study revealed that various intermediate factors like age of household head, education level of household head, livestock ownership, home gardening, total income, access to irrigation awareness of dietary diversity were found to positively influence household dietary diversity. However, distance from the market was found to be negatively associated with HDD. From the overall findings of the research, it is possible to deduce that the majority of the sampled populations were under medium dietary diversity calling for a holistic intervention with respect to enhancing household dietary diversity and consumption. Based on the findings of the study, we recommend that the regional and federal governments should provide access to education for households to broaden their understanding of the nutritional health benefits of a diverse diet and Yayu Agricultural and Natural Resources Office and stakeholders in the agricultural sector should promote and encourage availability of home gardening strategies, expand access to irrigation, introduce agricultural technologies to boost income of rural households and thus diversify their diet. Further, the regional and federal government should enhance awareness of the people on dietary diversity with community health workers and development agents, as well as media campaigns such as on the radio and TV programs and mobile messaging. Market infrastructure should be improved to enhance households' access to market that could contribute for improving household dietary diversity and consumption behavior. 
Table 7: Parameter estimates of ordinal logistic regression

\begin{tabular}{|c|c|c|c|c|c|}
\hline Variables & Estimate & Standard error & Wald & P-value & Odds ratio \\
\hline Sex & -0.059 & 0.513 & 0.013 & 0.908 & 0.942 \\
\hline Age & 0.302 & 0.073 & 17.115 & $0.000 * * *$ & 1.353 \\
\hline Education & 0.431 & 0.086 & 25.005 & $0.000 * * *$ & 1.538 \\
\hline HH sizet & 0.123 & 0.148 & 0.690 & 0.406 & 1.130 \\
\hline Land size & 0.219 & 0.174 & 1.592 & 0.207 & 1.245 \\
\hline Livestock & 0.322 & 0.130 & 6.164 & $0.013 * *$ & 1.380 \\
\hline Irrigation & 1.762 & 0.572 & 9.482 & $0.002 * * *$ & 5.824 \\
\hline Gardening & 1.089 & 0.472 & 5.313 & $0.021 * *$ & 2.970 \\
\hline Income & 0.184 & 0.059 & 9.723 & $0.002 * * *$ & 1.202 \\
\hline Market & -0.441 & 0.139 & 10.038 & $0.002 * * *$ & 0.643 \\
\hline Extensiont & 0.004 & 0.019 & 0.056 & 0.813 & 1.004 \\
\hline Inputst & -0.174 & 0.476 & 0.134 & 0.714 & 0.840 \\
\hline HEW & 0.064 & 0.053 & 1.431 & 0.232 & 1.066 \\
\hline Awareness & 1.395 & 0.512 & 7.429 & $0.006 * * *$ & 4.036 \\
\hline
\end{tabular}




\section{ACKNOWLEDGMENTS}

The authors would like to thank NutriHAF Africa project for financially supporting the research. We thank respondents in Yayu Biosphere Woreda for their willingness and patience to be part of this research.

\section{REFERENCES}

Abdulhalik Workicho, Tefera Belachew, Garuma Tolu, Beyene Wondafrash, Lachat, C., Verstraeten, R and Kolsteren, P. (2016). Household dietary diversity and animal source food consumption in Ethiopia: evidence from the 2011 Welfare Monitoring Survey. BioMed Central Public Health 16(1): 1192.

Admassu Tesso, Techane Gonfa and Gudrun, B.K. (2017). An Assessment of Household Dietary Diversity and Vegetable Consumption: Case Study of Smallholder Farmers in Yayu Biosphere Reserve, Ethiopia. Tropentag 2017, September 20 - 22, Bonn, Germany

Ajah, A.I., Agera, S.I.N and Ejembi, S.E. (2013). Prospects of the contribution of home gardens to food security in our households: Journal of Research in Forestry, Wildlife and Environment 5(1): 23-27

Alemayehu Seyoum, Dorosh, P and Sinafikeh Asrat. (2012). Crop production in Ethiopia: regional patterns and trends. Food and Agriculture in Ethiopia: Progress and Policy Challenges 74: 53.

Arega Bekele. (2014). The role of productive safety nets in improving household food dietary diversity in the Amhara Region of Ethiopia: A case study on Lay Gayint District. Ethiopian Journal of Health Development 28(3):191-201.

Bamidele, F.S., Abayomi, O and Esther, O.A. (2010). Economic analysis of rice consumption patterns in Nigeria. Journal of Agricultural Science and Technology 12(1):1-11.

Bundala, N., Eleraky, L., Kinabo, J., Jumbe, T., Stuetz, W., Bonatti, M., Biesalski, H., Mutabazi, K., Sieber, S and Rybak, C. (2017). Knowledge, behavior and practices on dietary diversity of rural households in Dodoma and Morogoro, Tanzania

Cabalda A.B., Rayco-Solon, P., Solon, J.A and Solon, F.S. (2011). Home gardening is associated with Filipino preschool children's dietary diversity. Journal of the American Dietetic Association 111(5): 711-71.

Daniels. C.M. (2009). Dietary diversity as a measure of women's diet quality in resource-poor areas: results from metropolitan Cebu, Philippines site. 
Washington: Food and Nutrition Technical Assistance II Project (FANTA-2)

Davidson, K.A and Kropp, J.D. (2017). Does market access improve dietary diversity? Evidence from Bangladesh. (No. 252854). Southern Agricultural Economics Association.

Degye Goshu, Belay Kassa and Mengistu Ketema. (2013). Measuring diet quantity and quality dimensions of food security in rural Ethiopia. Journal of Development and Agricultural Economics 5(5): 174-185.

Dillon A., McGee, K and Oseni, G. (2015). Agricultural production, dietary diversity, and climate variability. The Journal of Development Studies 51(8): 976-995.

EDHS (Ethiopia Demographic and Health Survey). (2011). Central Statistical Agency, Addis Ababa, Ethiopia and ICF International Calverton, Maryland, USA.

FAO, WFP and IFAD. (2012): The state of food insecurity in the world: Economic growth is necessary but not sufficient to accelerate reduction of hunger and malnutrition. FAO, Rome.

FAO. (2008) Developing food-based dietary guidelines: a manual from the English-speaking Caribbean, Rome 1-85.

FAO. (2013). WFP the state of food insecurity in the world 2013 the multiple dimensions of food security. FAO, Rome.

FDRE. (2013). Government of the Federal Democratic Republic of Ethiopia National Nutrition Program 2008-2015.

FMoH/UNICEF/EU. (2016). Situation analysis of the nutrition sector in Ethiopia: 2000-2015. Ethiopian Federal Ministry of Health, UNICEF and European Commission Delegation: Addis Ababa, Ethiopia

Fuller, F.H., Beghin, J.C and Rozelle, S. (2004). Urban Demand for Dairy Products in China: Evidence from New Survey Data.

Galhena, D.H., Freed, R and Maredia K.M. (2013). Home gardens: A promising approach to enhance household food security and wellbeing. Agriculture \& Food Security 2(1): 8.

Getnet Mekuria, Yalewsew Wubneh and Tilahun Tewabe. (2017). Household dietary diversity and associated factors among residents of Finote Selam town, North West Ethiopia: a cross sectional study. BioMed Central Nutrition 3(1): 28

Grace, D. (2016). Influencing food environment for healthy diets through food safety. FAO

Green, W.H. (2008). Econometric Analysis, sixth Edition. Upper Saddle River, Prentice hall, Inc., New Jersey

Gujarati, N. (1995). Basic Econometrics, $3^{\text {rd }}$ Edition, McGraw Hill Book Company, New York. 
Hamilton, L.C., 2006. Statistics with STATA: Updated for version 9. Duxbury, an imprint of Thomson Brooks. Cole, a part of The Thompson Corporation.

Headey, D and Ecker, O. (2012). Rethinking the measurement of food security: From first principles to best practice. Food Security 5(3): 327 343.

Herrador, Z., Perez-Formigo, J., Sordo, L., Gadisa, E., Moreno, J., Benito, A., Assefa, A and Custodio, E., (2015). Low dietary diversity and intake of animal source foods among school aged children in Libo Kemkem and Fogera Districts, Ethiopia. PloS one 10(7): 0133435

Hirvonen, K and Hoddinott, J. (2017). Agricultural production and children's diets: evidence from rural Ethiopia. Agricultural Economics 48(4): 469480.

IFPRI (International Food Policy Research Institute). (2015). Market access, welfare, and nutrition: Evidence from Ethiopia. Working Paper 77

IFPRI (International Food Policy Research Institute). (2018). Food system for health diets in Ethiopia: Discussion paper 1720

Jones, A.D., Shrinivas, A and Bezner-Kerr, R. (2014. Farm production diversity is associated with greater household dietary diversity in Malawi: findings from nationally representative data. Food Policy 46: 1-12

Keding, G.B., Msuya, J.M., Maass, B.L and Krawinkel, M.B., 2012. Relating dietary diversity and food variety scores to vegetable production and socio-economic status of women in rural Tanzania. Food Security 4(1): 129-140

Kennedy, G.L., Pedro, M.R., Seghieri, C., Nantel, G and Brouwer, I. (2007). Dietary diversity score is a useful indicator of micronutrient intake in nonbreast-feeding Filipino children. The Journal of Nutrition 137(2): 472477

Kibrom Sibhatu, Krishna, V and Qaim, M. (2015). Production diversity and dietary diversity in smallholder farm households. Proceedings of the National Academy of Sciences 112(34): 10657-10662

Koppmair, S., Kassie, M and Qaim, M. (2017). Farm production, market access and dietary diversity in Malawi. Public Health Nutrition 20(2): 325-335

Labadarios, D., Steyn, N.P and Nel, J. (2011). How diverse is the diet of adult South Africans? Nutrition Journal 10(1): 33

Linderhof, V., Powell, J., Vignes, R and Ruben, R. (2016). The influence of household farming systems on dietary diversity and caloric intake: the case of Uganda (No. 310-2016-5392). Paper presented at the 5th conference of the African Association of Agricultural Economist, 23-26 September 2016, Addis Ababa (Ethiopia)

Maddala, G.S. (1992). Limited Dependent and Quantitative Variables in Econometrics. Cambridge University Press. 
Mbwana, H.A., Kinabo, J., Lambert, C and Biesalski, H.K. (2016) Determinants of household dietarypractices in rural Tanzania: Implications for nutritioninterventions, Cogent Food \& Agriculture 2(1): 1224046.

Megersa Bekele, Markemann, A., Ayana Angassa, Zárate, A.V. (2014). The role of livestock diversification in ensuring household food security under a changing climate in Borana, Ethiopia. Food Security 6(1): 15-28

Mkemwa, T.H. (2015). Eating behaviors and dietary diversity among adults in Morogoro urban, Rural and Mvomero districts (Sokoine University of Agriculture)

Moyo, T and Machethe, C.L. (2016). The relationship between smallholder irrigation and household food availability and dietary diversity in Greater Tzaneen Municipality of Limpopo Province. Journal of Sustainable Development 9(4): 165.

Nguyen, P.H., Avula, R., Ruel, M.T., Saha, K.K., Ali, D., Tran, L.M., Frongillo, E.A., Menon, P and Rawat, R. (2013). Maternal and child dietary diversity are associated in Bangladesh, Vietnam, and Ethiopia. Journal of Nutrition 143(7): 1176-1183.

Nsele, N. (2014). The effect of seasonal food variety and dietary diversity on the nutritional status of a rural community in Kwa Zulu-Natal. Doctoral Dissertation, Durban University of Technology, South Africa.

Ochieng, J., Afari-Sefa, V., Lukumay, P.J and Dubois, T. (2017). Determinants of dietary diversity and the potential role of men in improving household nutrition in Tanzania. PloS one 12(12): 0189022.

Powell, B., Kerr, R.B., Young, S.L and Johns, T. (2017). The determinants of dietary diversity and nutrition: ethno nutrition knowledge of local people in the East Usambara Mountains, Tanzania. Journal of Ethnobiology and Ethnomedicine 13(1): 23

Rashid, D.A., Smith, L.C and Rahman, T. (2011). Determinants of dietary quality: evidence from Bangladesh. World Development, 39(12): 22212231.

Romeo, A., Meerman, J., Demeke, M., Scognamillo, A and Asfaw, S. (2016). Linking farm diversification to household diet diversification: evidence from a sample of Kenyan ultra-poor farmers. Food Security 8(6): 10691085.

Ruel, M.T., Harris, J and Cunningham, K. (2013). Diet quality in developing countries. In: Diet quality (239-261). Humana Press, New York, NY.

Schwei, R.J., Tesfay, H., Asfaw, F., Jogo, W and Busse, H. (2017). Household dietary diversity, vitamin A consumption and food security in rural Tigray, Ethiopia. Public Health Nutrition 20(9): 1540-1547

Smith, L., Alderman, H and Aduayom, D. (2006). Food insecurity in SubSaharan Africa: New estimates from household expenditure surveys (International Food Policy Research Institute, Washington, DC). 
Steyn, NP., Nel, JH., Nantel, G., Kennedy, G and Labadarios, D. (2006). Food variety and dietary diversity scores in children: are they good indicators of dietary adequacy? Public Health Nutrition 9(5): 644-650.

Stifel, D and Minten, B. (2017). Market access, well-being, and nutrition: evidence from Ethiopia. World Development 90:.229-241.

Tadesse Kuma, Mekidem Dereje and Minten, B. (2016). Coffee income, food security and diet diversity of smallholder coffee growers in Ethiopia. Ethiopian Development Research Institute working paper 15. Addis Ababa, Ethiopia.

Taruvinga, A., Muchenje, V and Mushunje, A. (2013). Determinants of rural household dietary diversity: The case of Amatole and Nyandeni districts, South Africa. International Journal of Development and Sustainability 2(4): 2233-2247.

Thompson, B and Meerman, J. (2014). Towards long-term nutrition security: The role of agriculture in dietary diversity. Improving Diets and Nutrition, p.246. The Food and Agriculture Organization of the United Nations and CABI Rome, FAO and Wallingford, UK, CABI

Tizita Damtew. (2017). The Effect of Small-scale Irrigation on Household Food Security in Bona Zuria Woreda, Sidama zone, Southern Ethiopia. Doctoral dissertation Hawassa University

Vakili, M., Abedi, P., Sharifi, M and Hosseini, M. (2013). Dietary diversity and its related factors among adolescents: a survey. Ahvaz-Iran Global Journal of Health Science 5(2): 181

Zarihun Kebebew, Wayessa Garedew and Adugna Debela. (2011). Understanding home garden in household food security strategy: Case study around Jimma, southwestern Ethiopia. Research Journal and Applied Science 6(1): 38-43 